\title{
ENHANCEMENT OF SOLUBILITY AND DISSOULTION RATE OF DOMPERIDONE USING COGRINDING AND KNEADING TECHNIQUE
}

\author{
*Tyagi Reena, Dhillon Vandana \\ Department of Pharmacy, Lloyd Institute of Management \& Technology, Plot - 11, Greater Noida, U. P., INDIA \\ Corresponding Author's E-mail ID- vandanadhillon@gmail.com, Mobile: +919999708884 \\ Received 13 June 2012; Review Completed 13 July 2012; Accepted 13 July 2012, Available online 15 July 2012
}

\begin{abstract}
Purpose: Improving the solubility and dissolution rate of domperidone using PEG 4000 and PVP K25 as a carriers in combination by Solid Dispersion Technique. Methods: Solid dispersions of domperidone were prepared using different ratios of PVP and PEG as carrier by co grinding and kneading method. The co grinding mixtures were prepared by mixing appropriate amounts of drug and carriers in different mass ratio in mortar and pestle. In kneading method, minimum quantity of water-ethanol mixture was used for dispersion of drug and carriers. The prepared solid dispersions were characterized for their drug content, invitro dissolution studies, FTIR spectroscopy and DSC were performed to identify phy siochemical interaction between the drug and carrier and its effect on dissolution behavior. A comparative evaluation of the dissolution profiles of domperidone solid dispersion tablets and marketed formulation (tablet) was carried out. Results: The prepared formulations showed marked improvement in the solubility and dissolution rate of drug which may be due to decrease in crystallinity of drug and additives. Formulation (S2) 1:2:2 of DOM:PEG:PVP gives fast dissolution rate 85.77\% of drug as compared to others formulation and marketed product (MP) in $1 \mathrm{hr}$. Conclusion: The prepared solid dispersion of the Domperidone with PEG and PVP can improve the solubility and dissolution rate of the drug.
\end{abstract}

Keywords: Domperidone, PEG, PVP, Solid dispersion, Dissolution rate.

\section{INTRODUCTION}

Poorly water-soluble drugs often require high doses in order to reach therapeutic plasma concentrations after oral administration. Improvement in the extent and rate of dissolution is highly desirable for such compounds, as this can lead to an increased and more reproducible oral bioavailability and subsequently to clinically relevant dose reduction and more reliable therapy. Numerous works have been carried out in order to modify the dissolution kinetics of poorly soluble drugs to improve their bioavailability ${ }^{1}$. Experience with solid dispersions over the last 20-30 years indicates that this is a very fruitful approach to improving the solubility, dissolution rates and consequently the bioavailability of poorly soluble drugs ${ }^{2}$. A number of insoluble drugs has shown to improve their dissolution character when converted to solid dispersion. Solid dispersion is used to produce a homogeneous distribution of a small amount of drug in solid state ${ }^{3}$.

The concept of SDs was introduced in 1961 by Sekiguchi and $\mathrm{Obi}^{4}$ in which the drug is dispersed in inert water soluble carrier at solid state. Solid dispersion technology is a well known process used to increase the dissolution kinetics and oral absorption of poorly water soluble drugs using water soluble inert carriers 5 . The use of hydrophilic polymers as carriers for the dissolution enhancement of poorly water-soluble drug is increasing ${ }^{6}$. Several water soluble carriers such as mannitol, urea, lactose, citric acid, polyvinyl pyrrolidone (PVP) and polyethylene glycols (PEG) are used as carriers for $\mathrm{SDs}^{7}$.

Domperidone is described chemically as 5-chloro-1-[1-[3(2, 3-dihydro-2-o xo-1H-benzimidazole-1-yl) propyl] - 4 piperidiny l ] - 1, 3-dihydro - $2 \mathrm{H}$ - benzimidazole -2-one ${ }^{8}$.
The drug is a benzimidazole derivative with a molecular weight of 426. According to biopharmaceutical classification system (BCS), domperidone is classified under class-II (poor solubility and high permeability). It acts as an antiemetic and a prokinetic agent through its effects on the chemoreceptor trigger zone and motor function of the stomach and small intestine. Unlike metoclopramide, it does not cause any adverse neurological symptoms as it has minimal penetration through the blood-brain barrier. It thus provides an excellent safety profile for long-term admin istration orally in the recommended doses 9 .

When given as immediate release tablet onset of action is half an hour and the drug effect lasts for 4-7h. The elimination half life is 5-7 $\mathrm{hr}$ and protein binding of Domperidone is 91-93\%. Although, Domperidone is a weak base with good solubility in acidic $\mathrm{pH}$ but in alkaline $\mathrm{pH}$, its solubility is significantly reduced ${ }^{10}$. It has poor aqueous solubility $(0.986 \mathrm{mg} / \mathrm{L})$ and the oral bioavailability of Domperidone has been reported at the range of 13-17\%. The poor aqueous solubility may be one possible reason for its low bioavailability. In order to increase the bioavailability of domperidone, a controlled release dosage form has been prepared to increase the solubility of Domperidone in the alkaline mediu $\mathrm{m}^{9}$.

Present study was designed to study the effect of PEG 4000 and PVP K25 as a water soluble carrier on solubility and dissolution rate of domperidone. Effect of drug to carrier ratios on the dissolution of domperidone was also studied. Solid Dispersion was prepared by co grinding and kneading method to compare rates of release of drug. The 
Solid Dispersions seems to possess great potential to significantly enhance the solubility and dissolution rate of domperidone.

\section{MATERIAL AND METHODS}

Domperidone was received as gift sample from Cotec Pharma (Roorkee, India). PEG 4000 was procured from Titan Biotech Ltd., Bhiwadi and PVP K25, Lactose, Starch was procured from $\mathrm{CDH}$, New Delhi. Distilled water was used throughout the study and all the other chemicals used were of analytical grade.

\section{PREPARATION OF SOLID DISPERSIONS OF DOMPERIDONE}

Solid dispersions were prepared with two carriers i.e. PEG 4000 and PVP K25 by two different methods i.e. cogrinding and kneading method.
Cogrinding method: The cogrinding mixtures of Domperidone were prepared using PEG 4000 and PVP $\mathrm{K} 25$ as carriers in combination in various weight ratios in a mortar and pestle and cogrinded for 5 minutes. The dry mass was pulverized by passing through sieve no. 60 . The dried mass was stored in dessicator until further use.

Kneading method: A mixture of Domperidone, PEG 4000 and PVP K25 in different ratios were wetted with water-ethanol (1:1) mixture and kneaded thoroughly for 30 minutes in a glass mortar. The paste formed was dried in an oven at $40^{\circ} \mathrm{C}$ until dry. Dried powder was scrapped, crushed, pulverized and passed through sieve no 60 and stored in dessicator.

Table 1: Formu lation of solid dispersions of Domperidone

\begin{tabular}{|c|c|c|c|c|}
\hline For mul ation Code & Domperidone (mg) & PEG 4000 (mg) & PVP K 25 (mg) & Method \\
\hline F1 & 10 & 20 & 10 & Cogrinding \\
\hline F2 & 10 & 20 & 20 & Cogrinding \\
\hline F3 & 10 & 20 & 30 & Cogrinding \\
\hline S1 & 10 & 20 & 10 & Kneading \\
\hline S2 & 10 & 20 & 20 & Kneading \\
\hline S3 & 10 & 20 & 30 & Kneading \\
\hline
\end{tabular}

\section{Determination of percent yield ${ }^{11}$}

The percent yield of domperidone solid dispersions can be determined by using the following expression:

Percent yield $=$ (weight of prepared solid dispersion / weight of drug + carriers ) $\times 100$

\section{Preparation of Domperidone solid dis persion tablets}

The required quantities of domperidone solid dispersion, lactose (qs), talc (1\%) and magnesium stearate (1\%) were mixed thoroughly in a dry mortar. The dried mass was passed through mesh no.60 to break the aggregates. The blend was compressed into $100 \mathrm{mg}$ tablets on a rotary tablet punching machine with punch size of using $9 \mathrm{~mm}$ round and flat punches by direct compression as per the formula given in Table 2.

Evaluation of Tablets: All the tablets prepared were evaluated for content of active ingredient, hardness, friability, disintegration time, dissolution rate as per official (I.P) methods. Hardness of tablets was tested using Monsanto hardness tester. Friability of the tablets was determined in a Roche friabilator. Disintegration time was determined in a tablet disintegration test machine using $900 \mathrm{ml}$ 0.1M HCL as the dissolution media ${ }^{12}$.

\section{Drug Content Es timation}

Drug content was determined by weighing randomly selected tablets, pulverizing to a fine powder. The powder equivalent to $10 \mathrm{mg}$ domperidone was weighed and dissolved in $10 \mathrm{ml}$ of methanol in volumetric flask using magnetic stirrer, the volume was adjusted to $100 \mathrm{ml}$ with $0.1 \mathrm{M} \mathrm{Hcl}$ and the solution was filtered. An aliquot of 1.0 $\mathrm{ml}$ of solution were diluted to $10 \mathrm{ml} 0.1 \mathrm{M} \mathrm{Hcl}$ in separate volumetric flask. The drug content in was determined spectrophotometrically at $284 \mathrm{~nm}(\lambda \max )^{13}$.

Table 2: Preparation of tablets of Solid dispersion

\begin{tabular}{|c|c|c|c|c|c|c|}
\hline Ingredients & F1 $(\mathbf{m g})$ & F2( mg) & F3(mg) & S1(mg) & S2(mg) & S3(mg) \\
\hline $\begin{array}{c}\text { Solid dis persion (containing 10mg of } \\
\text { domperi done) }\end{array}$ & 40 & 50 & 60 & 40 & 50 & 60 \\
\hline Lactose & 33 & 23 & 13 & 33 & 23 & 13 \\
\hline Starch & 25 & 25 & 25 & 25 & 25 & 25 \\
\hline Magnesium stear ate & 1 & 1 & 1 & 1 & 1 & 1 \\
\hline Talc & 1 & 1 & 1 & 1 & 1 & 1 \\
\hline Total weight & $100 \mathrm{mg}$ & $100 \mathrm{mg}$ & $100 \mathrm{mg}$ & $100 \mathrm{mg}$ & $100 \mathrm{mg}$ & $100 \mathrm{mg}$ \\
\hline
\end{tabular}




\section{Fourier-transform infrared (FTIR) s pectroscopy}

Fourier-transform infrared (FT-IR) spectra were recorded using an FT-IR spectrophotometer (Shimadzu). The samples (domperidone and its SDs) were previously ground and mixed thoroughly with potassium bromide, an infrared transparent matrix, at 1:5 (Sample: $\mathrm{KBr}$ ) ratio, respectively. The $\mathrm{KBr}$ discs were prepared by compressing the powders at a pressure of 5 tons for $5 \mathrm{~min}$ in a hydraulic press. The scanning range was $400-4700 \mathrm{~cm}-1^{14}$.

\section{Differential scanning calorimetry (DSC)}

A differential scanning calorimeter (DSC 7, PERKINELMER) at IIT Delhi was used to obtain the DSC curves representing the rates of heat uptake. About $5 \mathrm{mg}$ of sample was weighed in a standard open aluminum pan. An empty pan of the same type was used as the reference. Samples were heated from 50 to $300^{\circ} \mathrm{C}$ at a heating rate of $10{ }^{\circ} \mathrm{C} / \mathrm{min}$ while being purged with dry nitrogen. Calibrations of temperature and heat flow were performed with indiu $\mathrm{m}^{15}$.

\section{Dissolution studies :}

Dissolution studies were conducted using USP II paddle type dissolution apparatus by taking an accurately weighed amount of the prepared system equivalent to $10 \mathrm{mg}$ of the drug was added to each jar. The dissolution medium used was $900 \mathrm{ml}$ of $0.1 \mathrm{~N} \mathrm{HCl}$, maintained at $37 \pm 0.5{ }^{\circ} \mathrm{C}$ at a speed of $50 \mathrm{rpm}$. The dissolution study was performed for $1 \mathrm{hr} .5 \mathrm{ml}$ sample was withdrawn out at specified intervals of time and filtered. The in itial volume was maintained by adding $5 \mathrm{ml}$ of fresh dissolution medium to maintain a constant volume after each sampling. The removed samples were analy zed spectrophotometrically at $284.0 \mathrm{~nm}$ $(\lambda \max )$. Similarly a comparative in vitro drug release evaluation was also carried out between the prepared systems F1, F2, F3, S1, S2, S3 and a marketed formulation (tablet).

\section{RESULTS AND DISCUSS ION}

\section{Percentage Yield:}

The percent yield of domperidone solid dispersions ranged between 97 to $99 \%$.

Drug content: Results depicted in Table 3 shows that the drug concentration in solid dispersions ranged between 97.86 and $98.96 \%$.

Table 3: \% Drug content in Solid dispersion Formu lations

\begin{tabular}{|c|c|c|c|c|c|c|}
\hline For mulation code & F1 & F2 & F3 & S1 & S2 & S3 \\
\hline \% Drug Content & 97.86 & 98.91 & 98.85 & 98.2 & 98.96 & 97.93 \\
\hline
\end{tabular}

\section{Evaluation of prepared tablets}

Hardness, disintegration time and friability of all formulations were found between 4 to $6 \mathrm{~kg} / \mathrm{cm} 2,2.3$ to 6.5 $\min$ and 0.30 to $0.47 \%$. Release profile of all the formulation was shown in Figure 1. It was found that Batch S2 gives desirable fast release action. Moreover, hardness, disintegration time, and friability of S2 tablet were found $4 \pm 0.2 \mathrm{~kg} / \mathrm{cm} 2,2.3 \mathrm{~min}$ and $0.31 \%$.

\section{Dissolution Studies}

Dissolution profiles of prepared solid dispersion tablets and marketed samples in different media were studied is shown in figure 1, 2 and 3 . It is evident that the solid dispersion technique has improved the dissolution rate of domperidone to a great extent. The figure indicated that the formulation (S2) 1:2:2 of DOM:PEG:PVP gives fast dissolution rate $85.77 \%$ of drug in $0.1 \mathrm{M} \mathrm{Hcl}$ media as compared to formulation (F2) gives dissolution rate $83.80 \%$ of drug and marketed product (MP) dissolution rate $81.01 \%$ in one hour (Table 4). In pH 4.5 Acetate media, the percentage of drug release in one hour were (S2) $72.39 \%$, (F2) 69.44.14\% and(MP) $67.47 \%$ (Table 5). In $\mathrm{pH} 6.8$ Phosphate media, the percentage of drug release in one hour were (S2) $64.63 \%$, (F2 ) $62.24 \%$ and(MP) $60.25 \%$ (Table 6). The enhancement of dissolution of domperidone from the drug carrier may be due to several factors such as lack of crystallinity, increased wettability and dispersibility. Incorporation of drug with a hydrophilic carrier system offered an increased wetting and reduction in interfacial tension between hydrophobic drug and dissolution medium. The order of efficiencies of products based on percentage drug release after 60 minutes is $\mathrm{S} 2>\mathrm{F} 2>$ marketed formulation $>\mathrm{S} 1>\mathrm{F} 1>\mathrm{S} 3>\mathrm{F} 3$.

Table 4: \% Drug release in 0.1M HCL buffer

\begin{tabular}{|c|c|c|c|c|c|c|c|}
\hline Time(min) & Market product (MP) & F1 & F2 & F3 & S1 & S2 & S3 \\
\hline $\mathbf{5}$ & 51.01 & 47.57 & 52.16 & 45.27 & 48.88 & 55.27 & 46.75 \\
\hline $\mathbf{1 0}$ & 52.00 & 49.70 & 53.80 & 46.91 & 50.52 & 57.57 & 49.04 \\
\hline $\mathbf{1 5}$ & 55.44 & 51.67 & 58.39 & 49.04 & 53.47 & 60.19 & 51.01 \\
\hline $\mathbf{3 0}$ & 73.96 & 69.37 & 75.60 & 66.91 & 71.34 & 77.90 & 67.73 \\
\hline $\mathbf{6 0}$ & 81.01 & 76.26 & 83.80 & 72.81 & 78.39 & 85.77 & 75.60 \\
\hline
\end{tabular}


Table 5: \% Drug release in $\mathrm{pH} 4.5$ Acetate buffer

\begin{tabular}{|c|c|c|c|c|c|c|c|}
\hline Time (min) & Market product (MP) & F1 & F2 & F3 & S1 & S2 & S3 \\
\hline $\mathbf{5}$ & 40.09 & 36.49 & 41.40 & 32.88 & 38.29 & 43.70 & 35.18 \\
\hline $\mathbf{1 0}$ & 41.73 & 37.96 & 42.88 & 34.52 & 40.26 & 45.50 & 36.98 \\
\hline $\mathbf{1 5}$ & 43.86 & 40.09 & 45.01 & 36.32 & 42.72 & 48.45 & 38.13 \\
\hline $\mathbf{3 0}$ & 57.63 & 53.37 & 60.09 & 49.11 & 55.67 & 63.21 & 52.06 \\
\hline $\mathbf{6 0}$ & 67.47 & 63.21 & 69.44 & 58.95 & 65.50 & 72.39 & 61.40 \\
\hline
\end{tabular}

Table 6: \% Drug release in $\mathrm{pH} 6.8$ Phosphate buffer

\begin{tabular}{|c|c|c|c|c|c|c|c|}
\hline Time(min) & Market product (MP) & F1 & F2 & F3 & S1 & S2 & S3 \\
\hline $\mathbf{5}$ & 18.03 & 16.44 & 20.82 & 13.65 & 17.24 & 23.61 & 15.25 \\
\hline $\mathbf{1 0}$ & 21.22 & 18.43 & 22.42 & 15.65 & 19.23 & 26.80 & 17.24 \\
\hline $\mathbf{1 5}$ & 24.41 & 20.03 & 26.80 & 18.03 & 22.81 & 29.58 & 19.63 \\
\hline $\mathbf{3 0}$ & 45.51 & 40.73 & 47.11 & 35.96 & 43.12 & 50.29 & 38.74 \\
\hline $\mathbf{6 0}$ & 60.25 & 55.47 & 62.24 & 50.29 & 57.06 & 64.63 & 53.08 \\
\hline
\end{tabular}

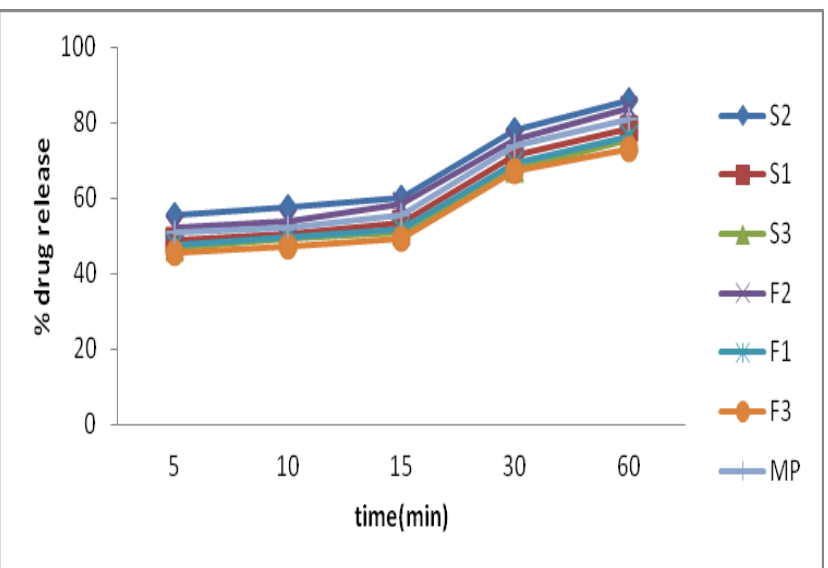

Figure 1: Comparative dissolution profiles of domperidone solid dispersion and marketed product (MP) in $0.1 \mathrm{M} \mathrm{Hcl}$ buffer

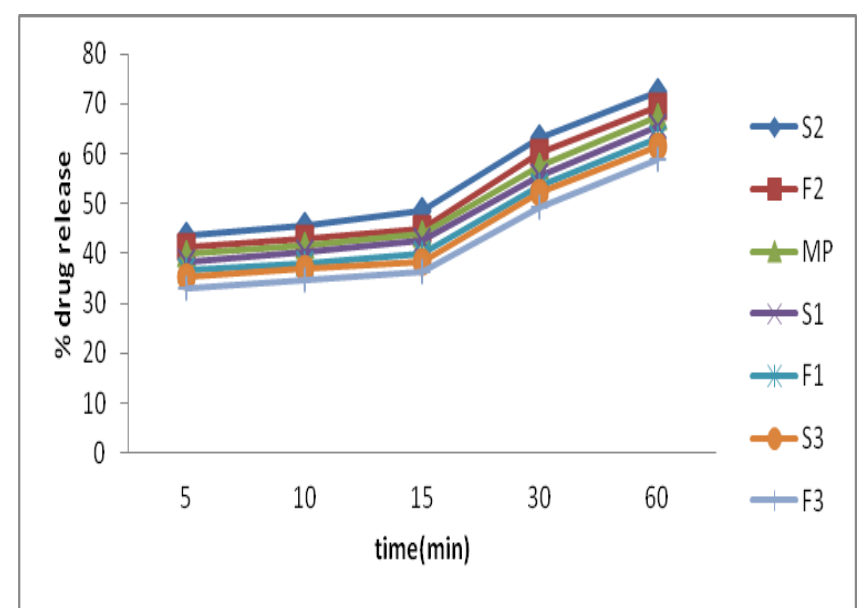

Figure 2: Comparative dissolution profiles of domperidone solid dispersion and marketed product (MP) in $\mathrm{pH} 4.5$ Acetate buffer

\section{Differential scanning calorimetry (DSC)}

The DSC curves of pure domperidone and its solid dispersion using PEG 4000 and PVP K 25 combination (S2) are shown in Fig. 7. The DSC curves of pure domperidone showed one sharp endothermic peak at $251.482^{\circ} \mathrm{C}$ corresponding to domperidone crystalline nature with enthalpy $(\Delta \mathrm{H})$ of $105.605 \mathrm{~J} / \mathrm{g}$. On the other hand, the DSC curves of domperidone solid dispersion using PEG 6000 and PVP K 30 combination showed two endothermic peaks, a sharp peak at $59.742^{\circ} \mathrm{C}$ corresponding to PEG with enthalpy $(\Delta \mathrm{H})$ of $70.472 \mathrm{~J} / \mathrm{g}$ and a broad peak at $212.580^{\circ} \mathrm{C}$ corresponding to domperidone in solid dispersion with enthalpy $(\Delta \mathrm{H})$ of $51.194 \mathrm{~J} / \mathrm{g}$. Peak temperature in solid dispersions shifted slightly to lower temperature with respect to the drug alone and there was a decrease in $\Delta H$ value of solid dispersion $(51.194 \mathrm{~J} / \mathrm{g}$ ) compared to the pure drug $(105.605 \mathrm{~J} / \mathrm{g})$. These phenomena could be attributed to the amorphous form of the drug in solid dispersions and indicating absence of crystalline drug.

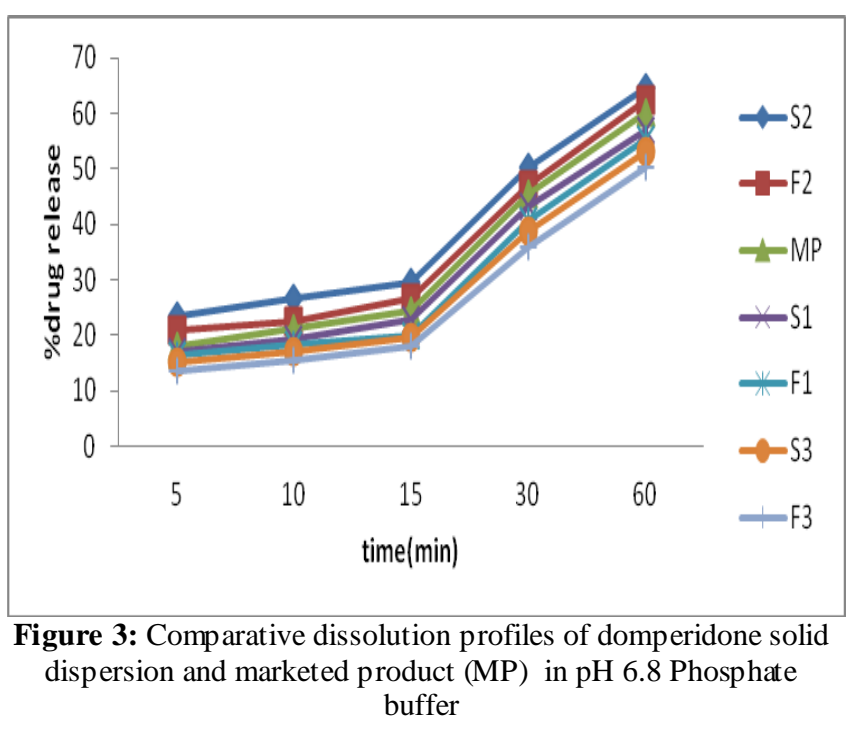

\section{Fourier transforms infrared (FTIR) s pectroscopy}

Fourier transform infrared spectroscopy was performed on pure domperidone (DMP) and its solid dispersion. Pure DMP spectra showed sharp characteristic peaks at $3360,1720,2818,1677$ and1488 $\mathrm{cm}-1$. All the above characteristic peaks appear in the spectra of domperidone solid dispersion at same wave number indicating no modification or interaction between the drug and carrier. 


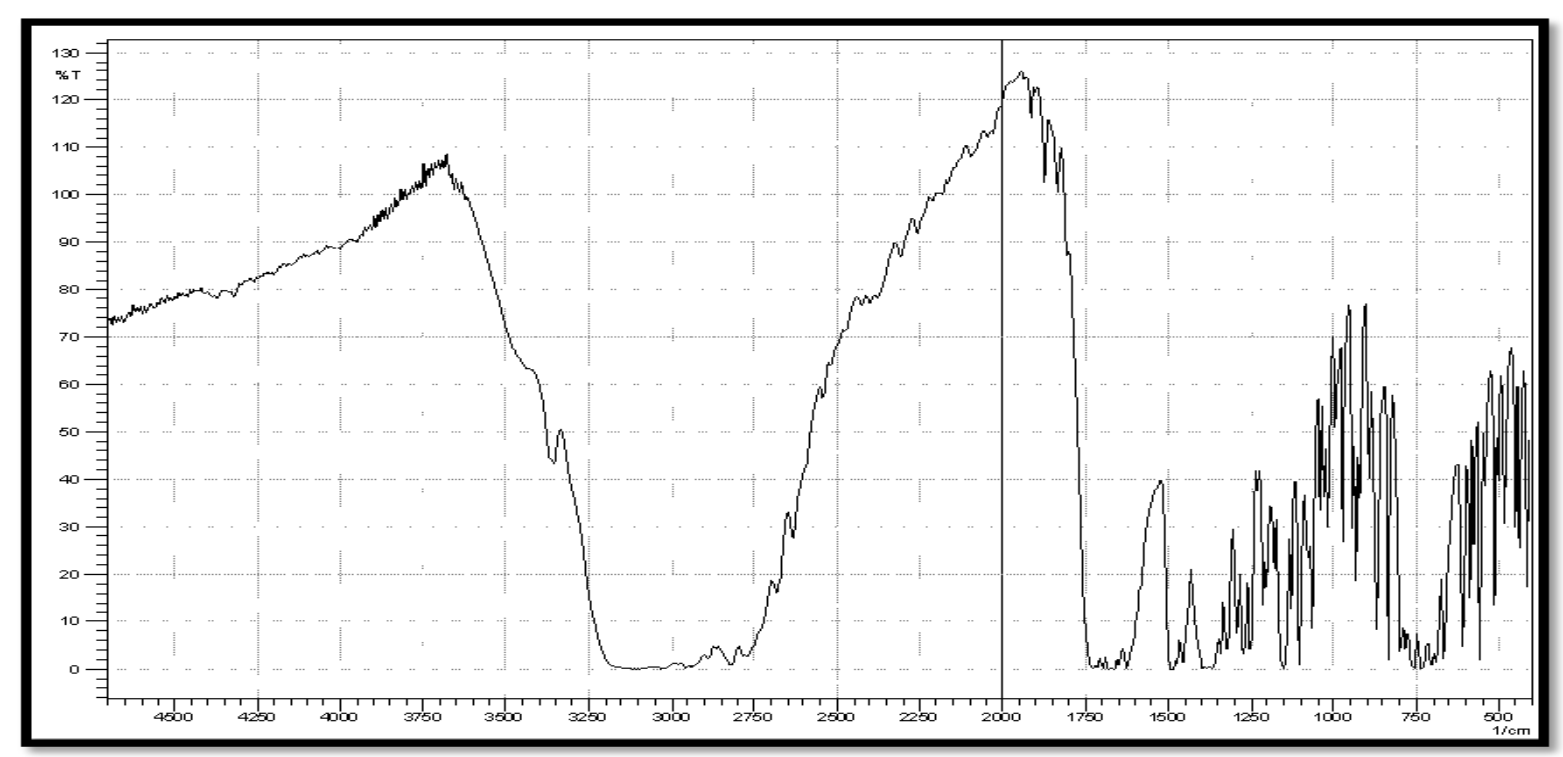

Figure 4: FTIR spectra of pure drug (Domperidone)

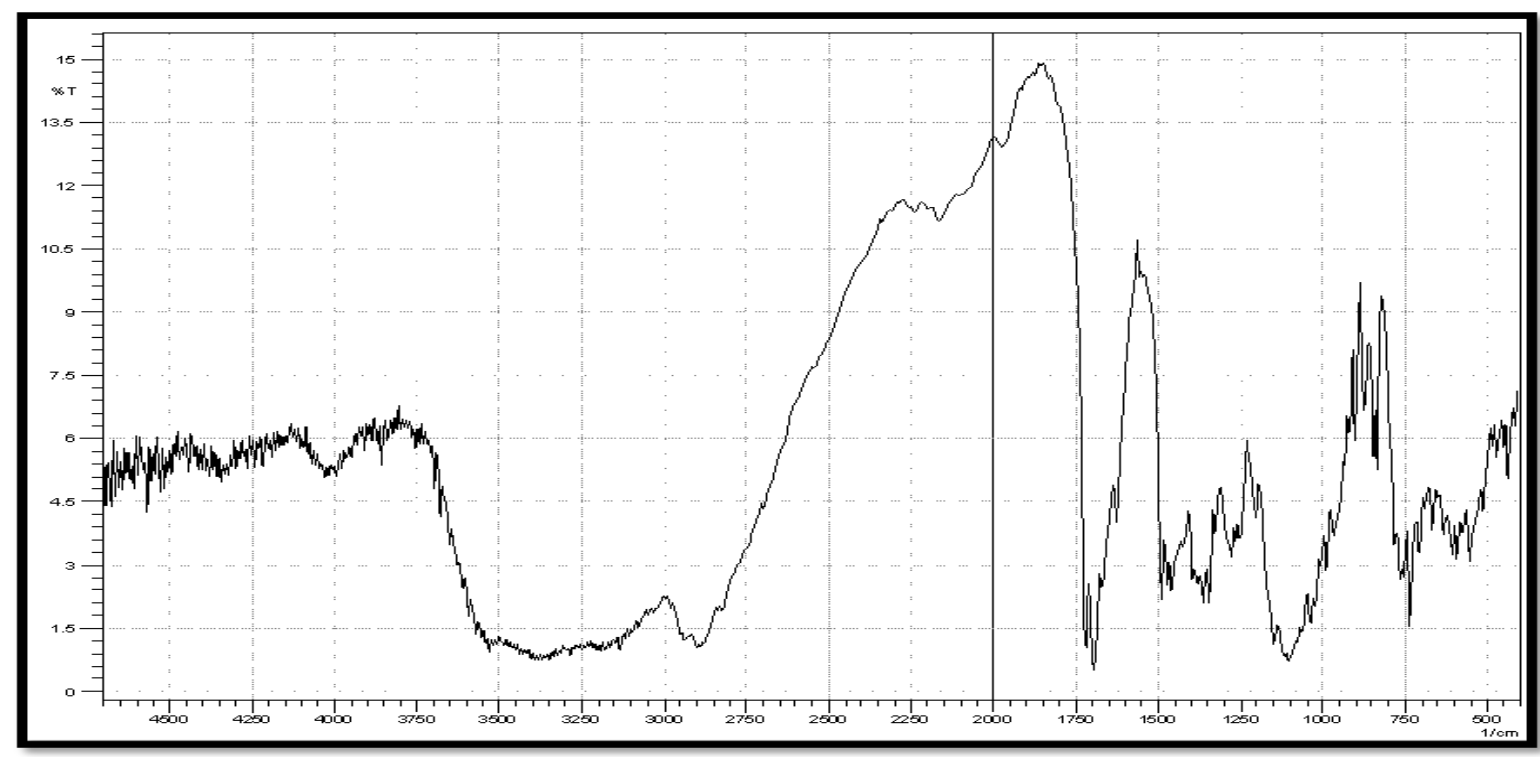

Figure 5: FTIR spectra of Domperidone + PEG 4000 + PVP K25 (1:2:2)

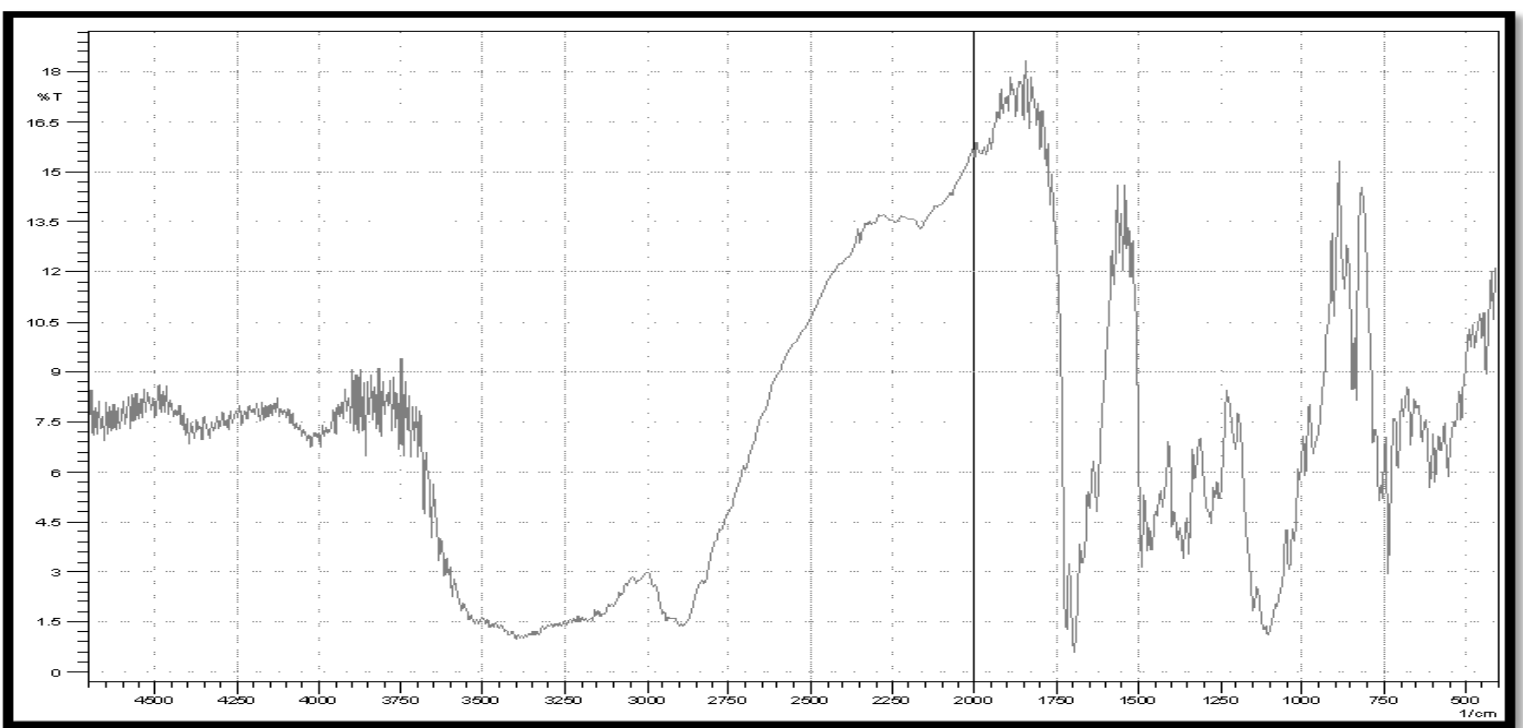

Figure 6: FTIR spectra of Domperidone + PEG 4000 + PVP K25 (1:2:1) 


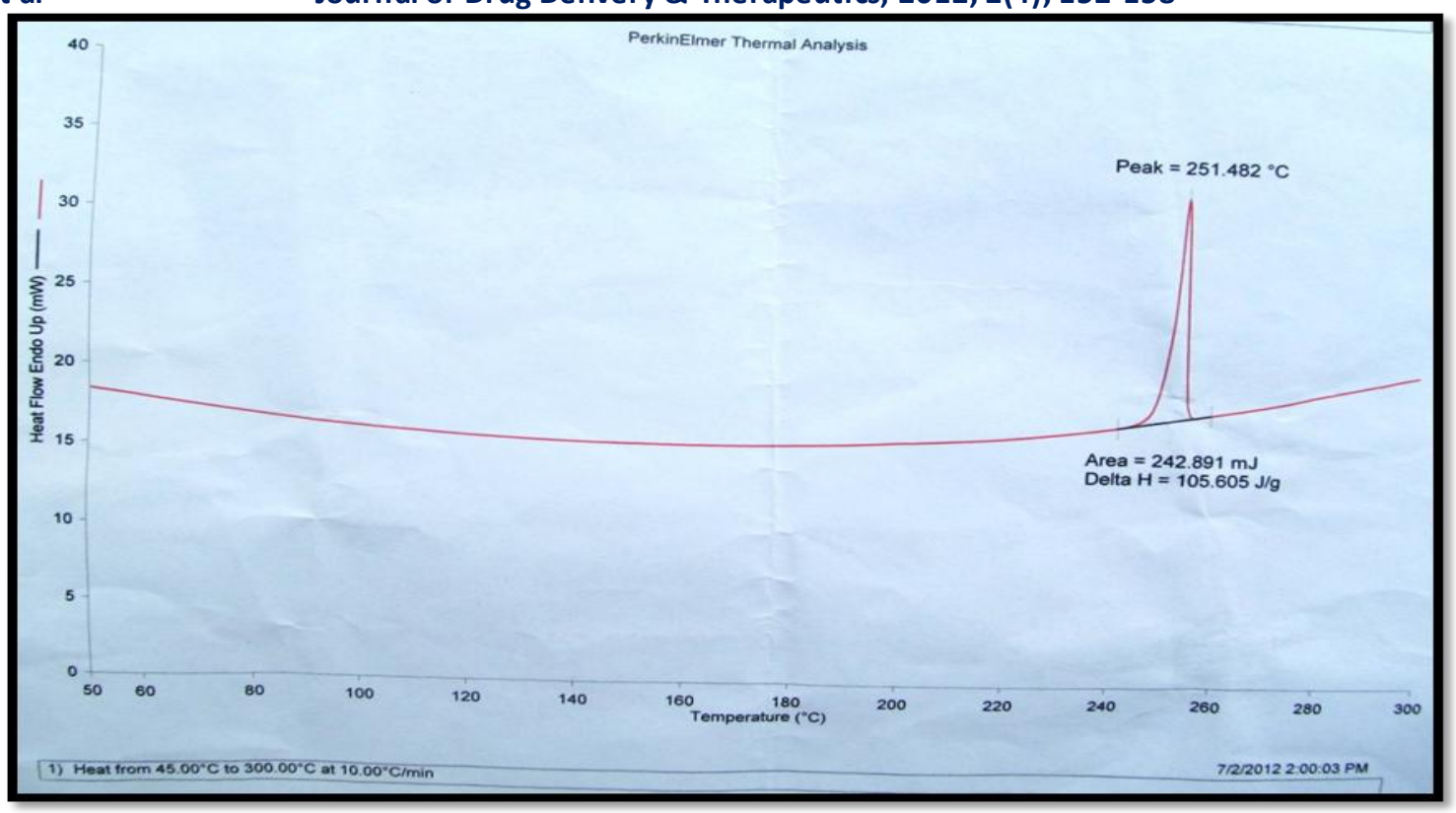

Figure 7: DSC curve of pure domperidone

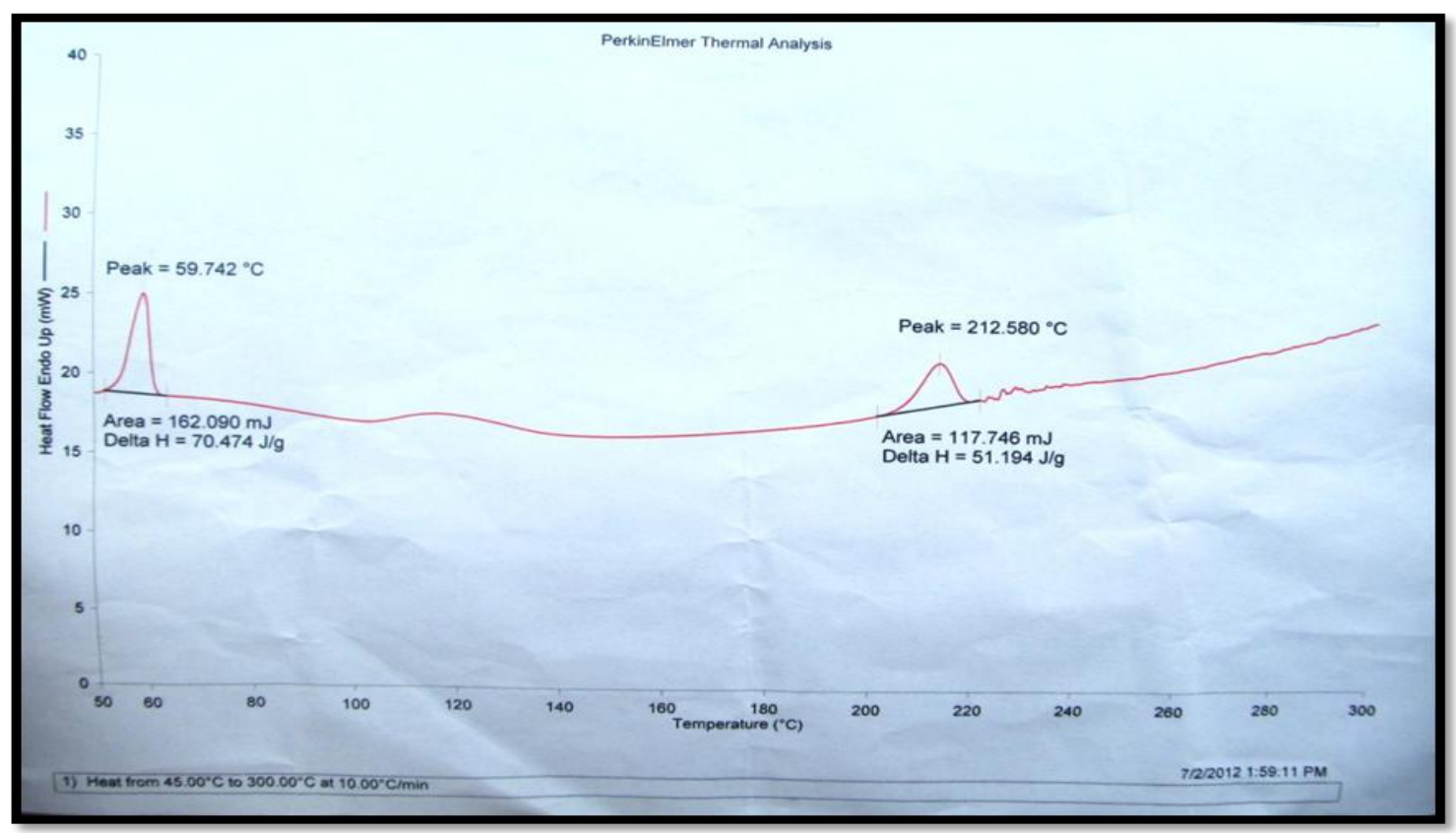

Figure 8: DSC curve of do mperidone + PEG 4000 + PVP K25 (1:2:1)

\section{DISCUSS ION}

The enhancement of dis solution of domperidone from drug carrier systems can be described to several other factors also. Lack of crystallinity, i.e. amorphization, increased wettability, dispersibility and particle size reduction are considered to be important factors for dissolution rate enhancement. As indicative from dissolution data of cogrinding mixtures, improvement could be attributed to higher wettability and dispersibility. Dry mixing of drug with a hydrophilic carrier results in greater wetting and increases surface available for dissolution by reducing interfacial tension between hydrophobic drug and dissolution media. Furthermore, kneading results in uniform distribution of drug in the polymer crust in a highly dispersed state. Thus, when such a system comes in (c) 2011, JDDT. All Rights Reserved contact with an aqueous dissolution medium, the hydrophilic carrier dissolves and results in precipitation of the embedded drug into fine particles, which increase the dissolution surface available. Moreover, other factors such as absence of aggregation and/or reagglomeration phenomenon during dissolution and particle size reduction could be attributed to a better dis solution profile.

\section{CONCLUSION}

Domperidone is practically insoluble in water and aqueous fluids. As such the oral absorption of domperidone is dissolution rate limited. A mong the various approaches to improve the dissolution of poorly soluble drugs, the preparation of solid dispersions has often proven to be very successful; hydrophilic carrier was used in the preparation 
of solid dispersions and evaluated for their efficiency in increasing the dissolution rate of domperidone. Solid dispersions of domperidone in PEG and PVP were prepared as cogrinding mixture and by kneading method. The study shows that the dissolution rate of domperidone may be enhanced to a great extent by solid dispersion technique using kneading method.

\section{REFERENCES}

1. Guleria R, Sharma V, Kapoor A, Kaith NS, Singh R,"Polyethy lene Gylcol Enhances Solubility of Domperidone through Solid dispersion" AJPTR, 2012, 2(2), 630-638.

2. Arunachalam A, Karthikeyan M, Konam K, Prasad P, Sethuraman S, Ashutoshraman S, Solid Dispersions: A Review, CPR, 2010, 1(1), 82-90.

3. Rathore SD, Thakur RR, Narwal S, Solid dispersion a new horizon in novel drug delivery sy stem, JPR, 2012, 5(2), 10071014.

4. Sekiguchi K, Obi N, Studies on Absorption of Eutectic Mixture: A comparison of the behaviour of eutectic mixture of sulfathiazole and of ordinary sulfathiazole in man, Chem Pharm Bull, 1961, 9(9), 866-872.

5. Delahaye N, Duclos R, Saiter JM, Varnier S, Characterization of solid dispersions phase transitions using a new optical thermal analy zer, DDIP, 1997, 23(3), 293-303.

6. Okimoto K, Miyake M, Ibuki R, Yasumura M, Ohnishi N, Nakai T, "Dissolution mechanism and rate of Solid Dispersions particles of Nilvadine with Hydroxyl Propyl Methyl Cellulose" IJP, 1997, 159, 85-93.

7. Vadnere MK.. Encyclopedia Of Pharmaceutical Technology, In: Swarbrick J, Boylan JC, Marcel Dekker Inc, New York, 2002, 1(2), 641-648.

8. Swami G, Koshy MK, Pandey M, Saraf SA,"Preparation and Characterization of Domperidone beta Cyclodextrin

\section{ACKNOWLEDGMENT}

I am thankful to Cotec Pharma Pvt. Ltd, Roorkee for providing gift sample of Domperidone. I also wish to thank to staffs of the laboratory of Indian Institute of Technology New Delhi.

CONFLICT OF INTER ES T: The Authors declares that there is no conflict of interest.

complexes prepared by Kneading method" IJAPS, 2010, 1(1), 68-74.

9. Savio CR, Soykan I and Richard WM, Domperidone: Review of pharmacology and clinical applications in gastroenterology, AJG, 2007,102, 2036-2045.

10. Higuchi $\mathrm{T}$ and Conners $\mathrm{K}$. Phase Solubility techniques, Advances in Analytical Chemistry and Instrumentation. $4^{\text {th }}$ ed., 1965, 117-123.

11. Dixit AK, Singh RP, Singh S, Solid dispersion - A Strategy for improving the solubility of poorly soluble drugs, IJRPBS, 3(2), 960-966.

12. Gohel M, Patel M, Amin A, Agarwal R, Dave R, Bariya N,"Formulation Design and Optimization of Mouth Dissolve Tablets of Nimesulide Using Vaccum Drying Technique" AAPST, 5(3), 36.

13. Ghodke SD, Nakhat DP, Yeole GP, Naikwade SN, Shah RR,"Preparation and characterization of Domperidone inclusion complexes with cyclodextrin : influence of preparation method" IJPR, 2009, 8(3), 145-151.

14. Guleria R, Kaith NS, Singh R,"Improved Dissolution of Domperidone in Solid Dispersion with Polymeric Hydrophilic Additive" JCPR, 2011, 3(6), 655-664.

15. Patel K, Prasad KR, Bajpai M,"Enhancement of Dissolution Rate of Domperidone Using Melt Granulation Technique" SRL, 2011, 3(2), 25-33. 